\title{
SM01a AND SM01b TEST RESULTS
}

\author{
Mirco Coccoli \\ Luisa Chiesa \\ $2 / 18 / 2002$
}

\section{OVERVIEW}

This report is a summary of test results for the two magnets SM01a and SM01b, tested in December 2001 and January 2002. These two magnets differ only in their final assembly procedure.

In this table we summarize the main features of these magnets:

\begin{tabular}{|l|l|l|l|l|l|l|}
\hline COILS & STRANDS & $\mathbf{C u} / \mathbf{S c}$ & $\mathbf{I}_{\mathbf{s s}} \mathbf{( A )}$ & $\mathbf{J}_{\mathbf{c}}\left(\mathbf{A} / \mathbf{m m}^{\mathbf{2}}\right)$ & $\mathbf{J}_{\mathbf{c u}}(\mathbf{A} / \mathbf{m m} \mathbf{2})$ & $\mathbf{B}_{\mathbf{p k}}^{\text {(ss) }} \mathbf{( T )}$ \\
\hline SC01 & 20 & $44.9 / 55.1$ & 9871 & 2200 & 2698 & 11.882 \\
SC02 & & & & & & \\
\hline
\end{tabular}

Table 1 Main parameters for SM01a and SM01b.

As one can see the two magnets have the same two coils: SC-01 and SC-02. The first coil used welded skins and was cycled and pre-stressed with the standard procedure while SC-02 used the skins as simple spacers (not welded). The purpose was to see if this procedure affects the training behavior of the coil in terms of quench performance comparing directly the two techniques.

The main difference between the two magnets is the different pressure used in the final assembly (key insertion with different bladders pressure). SM01a was pressurized up to $13 \mathrm{kPsi}$ while SM01b was pressurized only up to $1.5 \mathrm{kPsi}$ so that the two coils were free to separate during current excitation. These two different assembly pressures showed an improved quench behavior in SM-01b, reaching a higher limit than in SM-01a.

Following is a brief description of all the measurements made including:

- Training history

- Ramp rate studies

- Strain measurements

- Spot heater studies

- RRR measurements

- Plus we would like to report initial studies of "slow and fast motions" recorded while the magnet was ramped to its critical current. 
SM01 a and b Test Results

||Seminole|Supercon $\mid$ Subscale Magnet Program $\mid$ SM First Series|SM01|Test Summar.doc

\section{TRAINING HISTORY}

\begin{tabular}{|c|c|c|c|}
\hline MAGNET & RAMP RATE (request) & Iq (A) & POSITION \\
\hline \multirow[t]{15}{*}{ SM01a } & $50 \mathrm{~A} / \mathrm{s}$ to $6 \mathrm{kA}, 16 \mathrm{~A} / \mathrm{s}$ to quench & 8885 & $\mathrm{SC}-02$ \\
\hline & “" & 8933 & SC-01 \\
\hline & “"” & 8924 & “"” \\
\hline & $6 "$ & 8817 & SC-02 \\
\hline & “" & 9137 & “"\% \\
\hline & “" & 9118 & “"” \\
\hline & “"” & 8933 & SC-01 \\
\hline & “"” & 8972 & SC-02 \\
\hline & “"” & 9205 & SC-01 \\
\hline & “" & 9234 & SC-02 \\
\hline & “"” & 9166 & SC-01 \\
\hline & (") & 9273 & SC-02 \\
\hline & (6) & 9351 & “"” \\
\hline & “" & 9341 & “"” \\
\hline & "“" & 9341 & SC-01 \\
\hline \multirow[t]{10}{*}{ SM01b } & $50 \mathrm{~A} / \mathrm{s}$ to $6 \mathrm{kA}, 16 \mathrm{~A} / \mathrm{s}$ to quench & 9661 & SC-01 \\
\hline & ،"’ (2) & 9651 & “"” \\
\hline & “"” & 9448 & SC-02 \\
\hline & “"” & 9680 & SC-01 \\
\hline & $50 \mathrm{~A} / \mathrm{s}$ to $6 \mathrm{kA}, 8 / \mathrm{s}$ to quench & 9845 & “"” \\
\hline & “"” & 9797 & “"” \\
\hline & $50 \mathrm{~A} / \mathrm{s}$ to $6 \mathrm{kA}, 4 / \mathrm{s}$ to quench & 9884 & $6 " \%$ \\
\hline & $50 \mathrm{~A} / \mathrm{s}$ to $6 \mathrm{kA}, 16 \mathrm{~A} / \mathrm{s}$ to quench & 9700 & “"” \\
\hline & $50 \mathrm{~A} / \mathrm{s}$ to $6 \mathrm{kA}, 4 / \mathrm{s}$ to quench & 9855 & 6 (6) \\
\hline & “" & 9874 & (") \\
\hline
\end{tabular}

Table 2 Quench history for SM01a and SM01b.

From the previous table we can observe several things:

- Even if SC01 was welded and pre-stressed with normal procedure while SC02 was simply spot-welded, we do not see any difference in quench behavior or a predominant number of quenches in one coil respect to the other.

- SM01b had a slow training towards the short sample limit after its first quench.

- As we can see the different assembly procedure produced a net increase in quench current of about $300 \mathrm{~A}$.

- In SM01b the only real training quench was Q\#4 (Iq=9448A) occurred in SC02. Data analysis revealed ramp rate dependence for all the other quenches (the quenches started suddenly and with no change in $\mathrm{dV} / \mathrm{dt}$ as a function of time). 
SM01 a and b Test Results

| SSeminole|Supercon $\mid$ Subscale Magnet Program $\mid$ SM First Series|SM01|Test Summar.doc
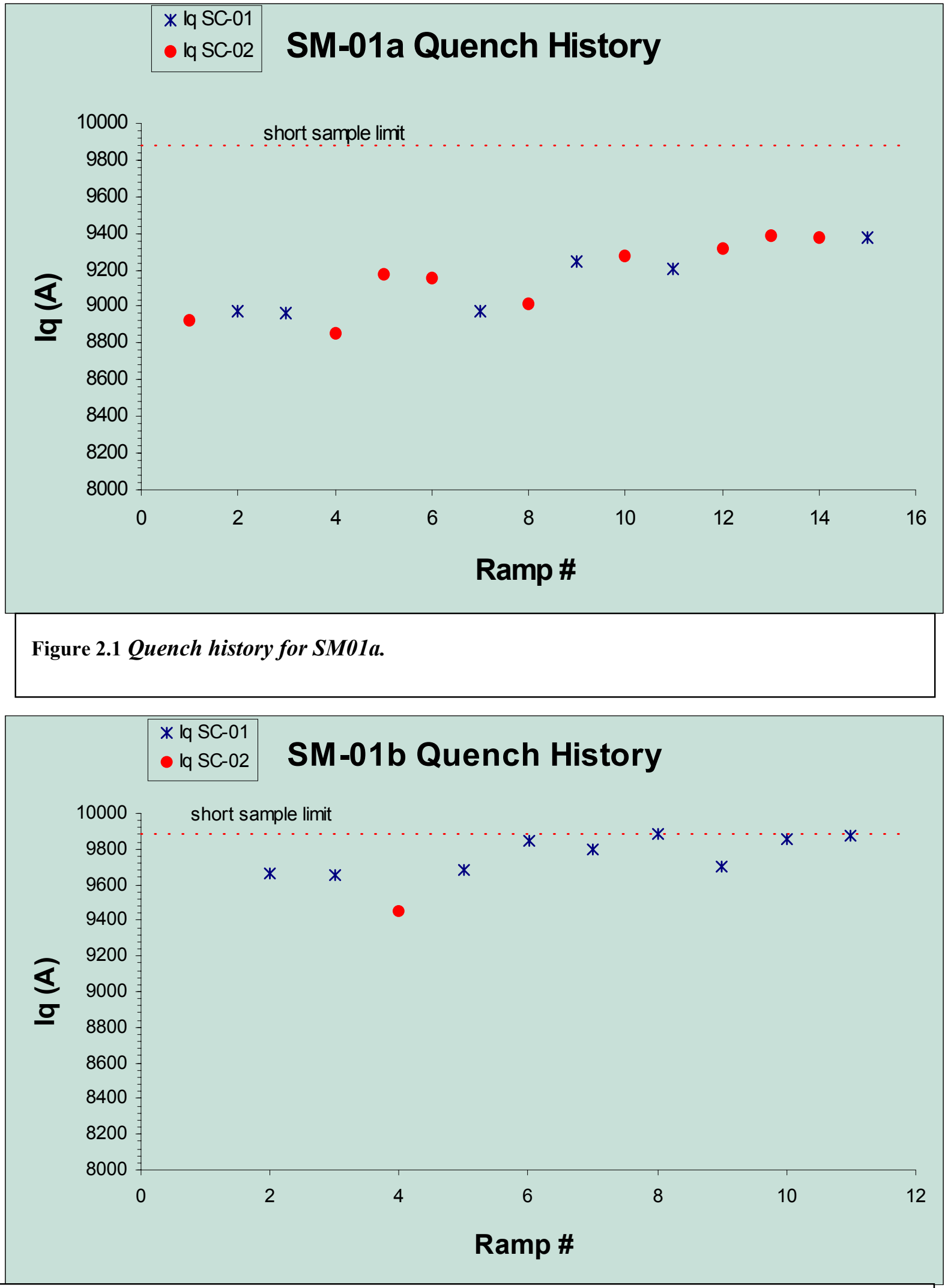

Figure 2.2 Quench history for SM01b.

MCoccoli@lbl.gov

LChiesa@1bl.gov

Page 3 of 16 


\section{SM01 a and b Test Results}

I|Seminole|Supercon|Subscale Magnet Program ISM First Series|SM01|Test Summar.doc

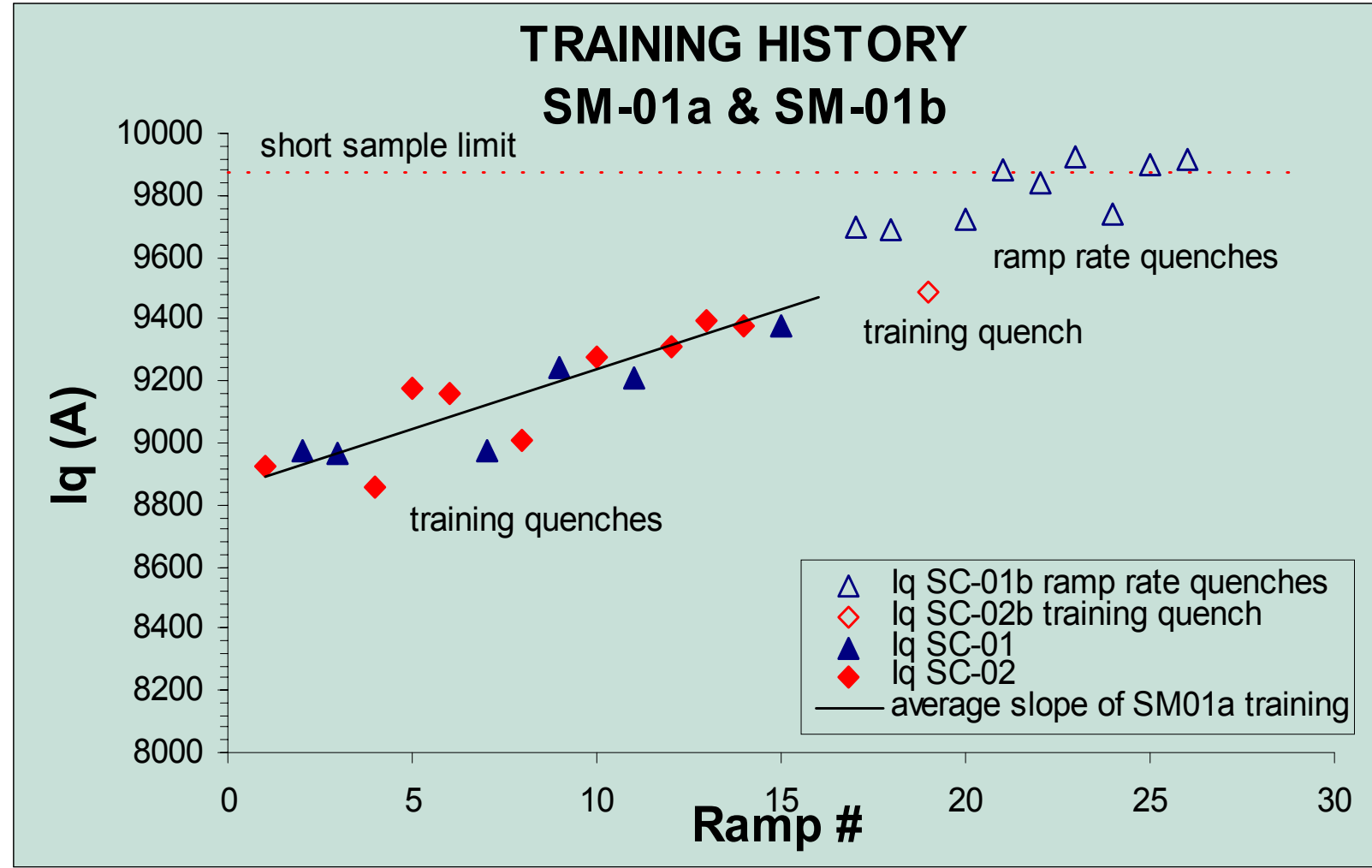

Figure 2.3 Quench history for SM01a and SM01b

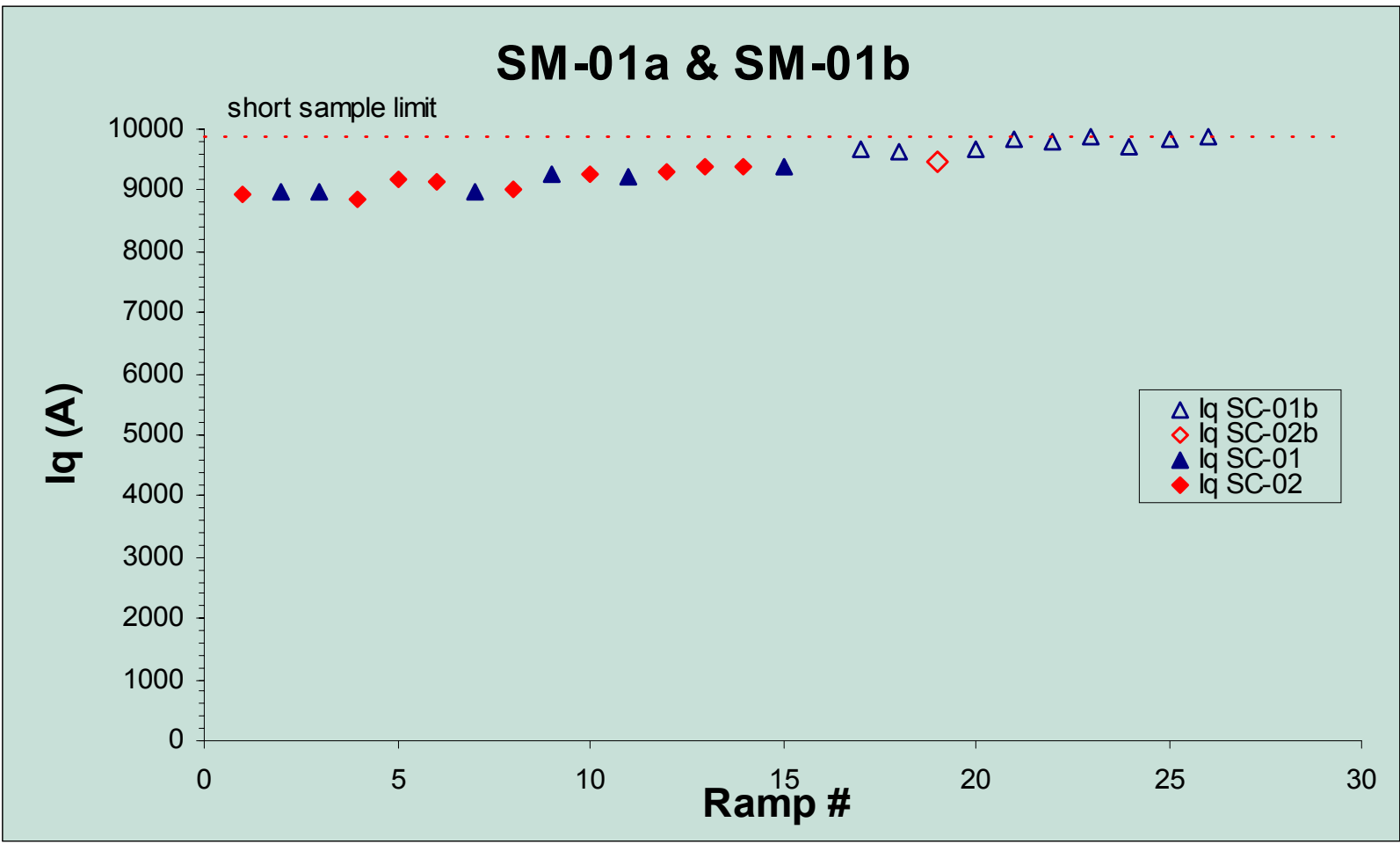

Figure 2.4 Quench history for SM01a and SM01b.

MCoccoli@lbl.gov

LChiesa@1bl.gov

Page 4 of 16 
SM01 a and b Test Results

||Seminole|Supercon $\mid$ Subscale Magnet Program $\mid$ SM First Series|SM01|Test Summar.doc

3. RAMP RATE STUDIES

In table 3 we summarize the results for ramp rate studies for SM01a and SM01b.

As already said in SM01b most of the quenches were ramp rate dependent with a very slow ramp rate (in principle reducing ramp rate as much as possible it is possible to extrapolate the short sample limit value for the current).

\begin{tabular}{|c|c|c|c|}
\hline MAGNET & RAMP RATE & $\operatorname{Iq}(\mathrm{A})$ & POSITION \\
\hline \multirow[t]{2}{*}{ SM01a } & 500 & 863 & SC01 \\
\hline & 250 & 1426 & $\mathrm{SC} 02$ \\
\hline without lead cooling & 125 & 3050 & “"” \\
\hline “"” & 70 & 2929 & $6 " \%$ \\
\hline \multirow[t]{6}{*}{ “"” } & 50 & 3957 & “"” \\
\hline & 16 & 9351 & $6 "$ \\
\hline & 70 & 8672 & '"י" \\
\hline & 100 & 8022 & SC01 \\
\hline & 175 & 4753 & “"” \\
\hline & 300 & 1290 & $6 "$ \\
\hline \multirow[t]{10}{*}{ SM01b } & 17.30 & 9661 & SC01 \\
\hline & 14.70 & 9651 & “"” \\
\hline & 16 & 9448 & $\mathrm{SC} 02$ \\
\hline & 17.10 & 9680 & SC01 \\
\hline & 7.90 & 9845 & '“" \\
\hline & 8.30 & 9797 & $6 " \%$ \\
\hline & 4.00 & 9884 & 6"” \\
\hline & 15.80 & 9700 & $6 " \%$ \\
\hline & 4.30 & 9855 & $6 "$ \\
\hline & 3.80 & 9874 & “"” \\
\hline
\end{tabular}

Table 3 Ramp rate studies for SM01a and SM01b. Ramp rates for SM01b were averaged over the last 20 s of data acquisition. Since we did not use slow ramp rates for SM01a it was not necessary to know the averaged ramp rate over the time.

The purpose of ramp rate studies was different for the two magnets. For SM01a we wanted to see the quench current behavior as a function of ramp rate (to determine where the kink occurs). Since this characteristic does not depend of the assembly of the magnet, in SM01b we did not repeat the same ramp rates but we reduced the ramp rate as much as possible to extrapolate the short sample value and compare it to the calculated one.

From the previous plot we can see a change in slope around $100 \mathrm{~A} / \mathrm{s}$ and a second change at around $250 \mathrm{~A} / \mathrm{s}$. Our uncertainty in these measurements is between $175 \mathrm{~A} / \mathrm{s}$ and $200 \mathrm{~A} / \mathrm{s}$ where we could have taken additional points and determine better the behavior of the magnet. The magnet shows degradation in quench current of more than $1000 \mathrm{~A}$ in the first $100 \mathrm{~A} / \mathrm{s}$ range indicating a coupling effect in the cable (eddy currents effect). This behavior can be crucial during acceleration cycle in an accelerator (the magnet could

MCoccoli@1bl.gov

LChiesa@,lbl.gov 


\section{SM01 a and b Test Results}

I|Seminole|Supercon $\mid$ Subscale Magnet Program $\mid$ SM First Series|SM01|Test Summar.doc quench while charging the machine) so it is necessary to understand the limit of the cables and better characterize its properties.

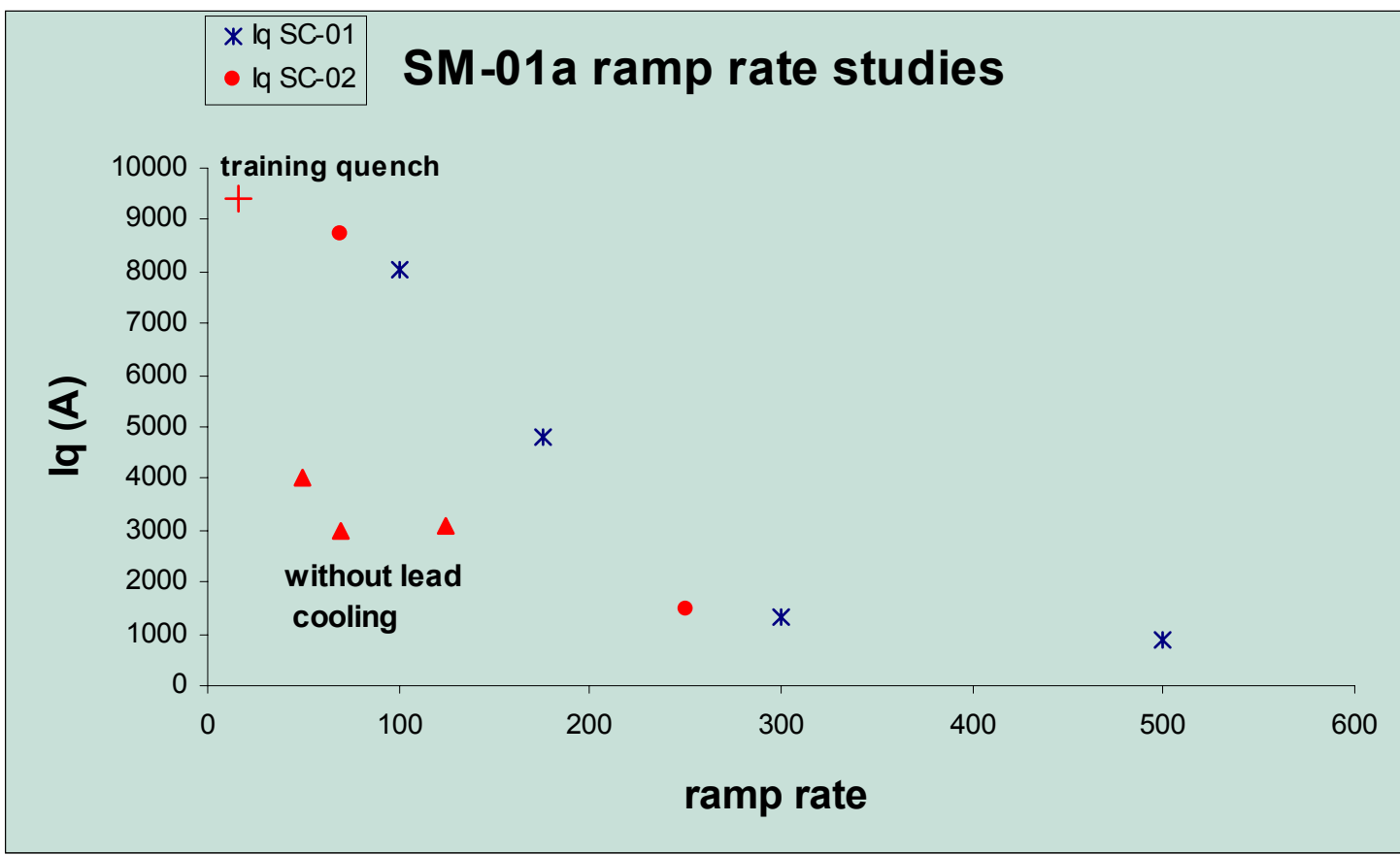

Figure 3.1 Quench current as a function of ramp rate for SM01a.

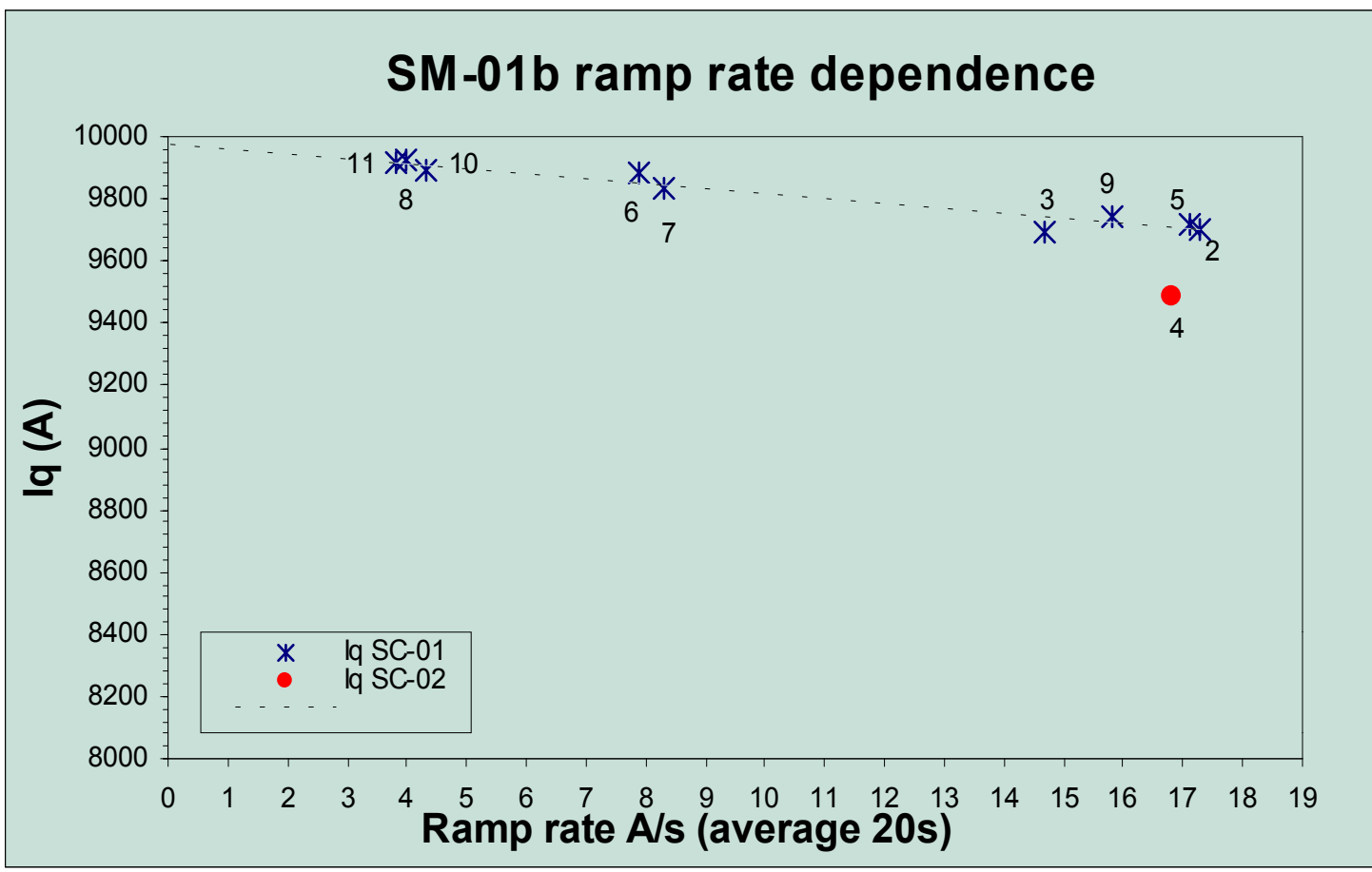

Figure 3.2 Quench current as a function of ramp rate for SM01b. Ramp rate values were averaged over the last 20 s of data acqusition. 
SM01 a and b Test Results

I|Seminole|Supercon $\mid$ Subscale Magnet Program $\mid S M$ First Series|SM01|Test Summar.doc

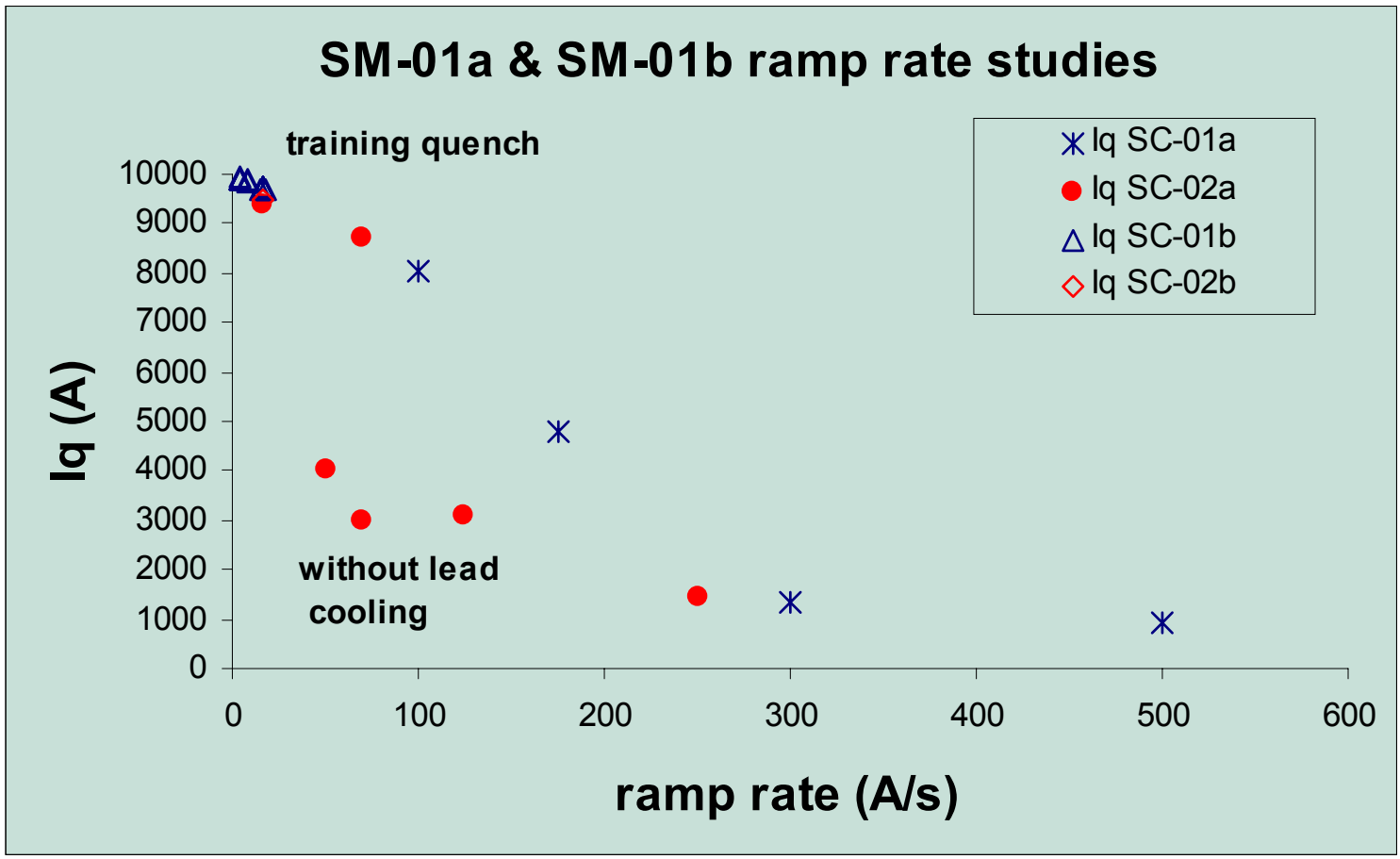

Figure 3.3 Quench current as function of ramp rate for SM01 a and SM01b. Ramp rate values were averaged over the last 20 s of data acquisition.

With the measures taken in SM01b, slow ramp rate, and extrapolating the values to $0 \mathrm{~A} / \mathrm{s}$ we reach a current of $9980 \mathrm{~A}$, which is consistent with the short sample limit predicted by calculations based of cables parameters. 
SM01 a and b Test Results

||Seminole|Supercon $\mid$ Subscale Magnet Program $\mid$ SM First Series|SM01|Test Summar.doc

\section{STRAIN MEASUREMENTS}

As already reported somewhere else, the overall pressure applied on SM01b is much lower than the one used for SM01a and this is reflected directly on strain measurements, as it will be shown later.

In particular in this second package (SM01b) the two coils were able to separate during current excitation. This effect can be clearly seen in the next plots where we can notice a "parabolic" growth in the shell strain as a function of current squared vs. a much lower linear growth recorded for SM01a during different quenches.

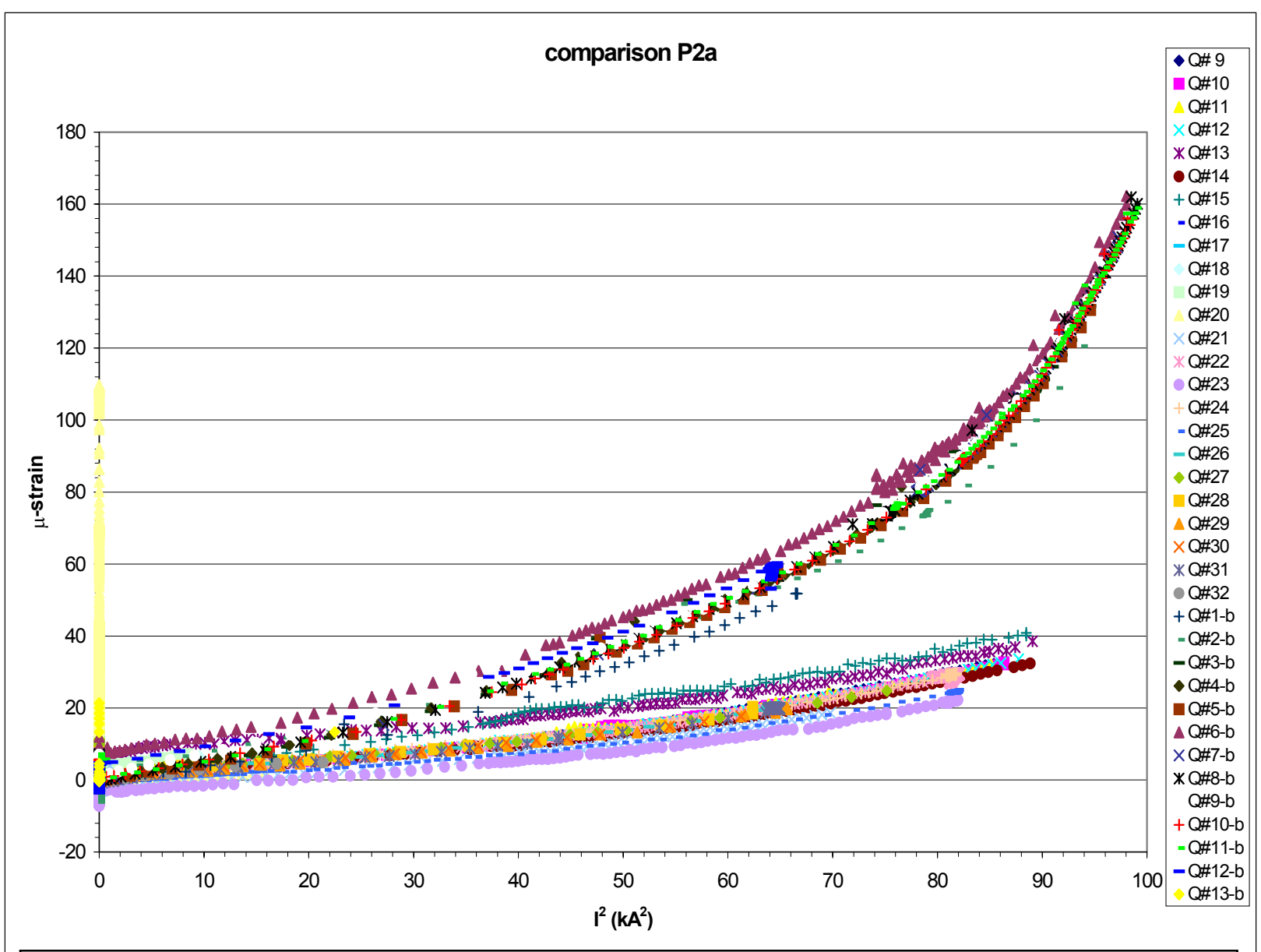

Figure 4.1 Strain measured in P2a gauge during different quenches in SM01a and SM01b.

It is easily noticeable that the current reached in SM01b is higher than in SM01a.As we can clearly see SM01a quenches have a linear behavior while SM01b quenches have different slopes indicating the separation between the two coils. The overall change in strain is almost three times higher in SM01b. 
SM01 a and b Test Results

| SSeminole|Supercon $\mid$ Subscale Magnet Program $\mid$ SM First Series $\mid$ SM01|Test Summar.doc

\section{SPOT HEATER STUDIES}

Each coil of the magnets (we used the same coil SC01 and SC02 for both of them) was equipped with a spot heater at lead end position on the most external turn of the winding. Spot heater events at $8 \mathrm{kA}$ and 9kA were induced in SM01a and only one event at 8kA in $\mathrm{SM} 01 \mathrm{~b}$. The main purpose of this test was to determine the minimum energy required to quench the magnet (parameter independent on the assembly so that SM01a and SM01b were the same for this kind of test).

The spot heater was charged with current and voltage read out with an oscilloscope. Then the discharge time for the spot was set at different time interval, increased by $10 \mathrm{~ms}$ each time till the magnet quenches. From the form of the voltage and current on the scope and from the time interval of the pulse we can easily calculate the energy put inside the magnet $\left(\mathrm{V}_{\text {average }} * \mathrm{I}_{\text {average }} * \Delta \mathrm{t}\right)$.

The measured resistances of the spot heaters plus their leads at room temperature were:

- SPOT HEATER COIL SC01 SH1 $3.6 \Omega$

- SPOT HEATER COIL SC02 SH2 $3.4 \Omega$

For their geometry and composition the spot heaters should have a resistance of $2.8 \Omega$ so a correction to the voltage read out from the spot was necessary. In this way we could take off the voltage due to the leads and evaluate correctly the energy put in the heaters.

Another correction is needed in case of quench, when the pulse of the spot is lasting over a time that exceeds the starting time of the quench (so that in reality the energy needed to quench is less than the total pulse put inside the spot). This correction can be done using the data acquisition system, which records the quench.

We summarize the measurements taken in table 3 and 4.

\begin{tabular}{|l|l|l|l|l|l|}
\hline SH-01 & $\mathbf{I}(\mathbf{k A})$ & $\Delta \mathbf{t}(\mathbf{m s})$ & $\mathbf{E}(\mathbf{J})$ & T $(\mathbf{K})$ & QUENCH \\
\hline & 8 & 0.074 & 0.438 & 272 & no \\
\hline & 8 & 0.098 & 0.665 & 375 & Q\#26 \\
\hline & 8 & 0.048 & 0.188 & 150 & no \\
\hline & 8 & 0.094 & 0.479 & 280 & no \\
\hline & 8 & 0.058 & 0.504 & 300 & Q\#12 (SM-01b) \\
\hline & 9 & 0.095 & 0.513 & 306 & Q\#24 \\
\hline & 9 & 0.073 & 0.442 & 275 & no \\
\hline & 9 & 0.088 & 0.497 & 298 & Q\#25 \\
\hline
\end{tabular}

Table 4 Spot heater measurements on spot heater SH01 (coil SC-01).

MCoccoli@lbl.gov

LChiesa@lbl.gov

Page 9 of 16 
SM01 a and b Test Results

| ISeminole|Supercon $\mid$ Subscale Magnet Program $\mid S M$ First Series|SM01|Test Summar.doc

\begin{tabular}{|l|l|l|l|l|l|}
\hline SH-02 & I (kA) & $\Delta \mathbf{t}(\mathbf{m s})$ & $\mathbf{E}(\mathbf{J})$ & T (K) & QUENCH \\
\hline & 8 & 0.087 & 0.536 & 316 & Q\#27 \\
\hline & 8 & 0.062 & 0.452 & 278 & Q\#30 \\
\hline & 8 & 0.064 & $\mathbf{0 . 3 1 7}$ & $\mathbf{2 1 7}$ & no \\
\hline & 8 & 0.047 & $\mathbf{0 . 2 8 4}$ & $\mathbf{2 0 2}$ & Q\#31 \\
\hline & 9 & 0.018 & 0.13 & 132 & no \\
\hline & 9 & 0.041 & 0.362 & 240 & Q\#22 \\
\hline & 9 & 0.063 & 0.352 & 233 & no \\
\hline & 9 & 0.051 & 0.375 & 244 & Q\#27 \\
\hline
\end{tabular}

Table 5 Spot heater measurements on spot heater SH02 (coil SC-02). The red values were not considered since the magnet had probably residual heating from previous quenches and we did not wait enough time to recover proper conditions.

During the test on $\mathrm{SH}-02$ at $8 \mathrm{kA}$ we did not have the proper condition to take data (not proper cooling) so we recorded two bad data (bold red values in table 4).

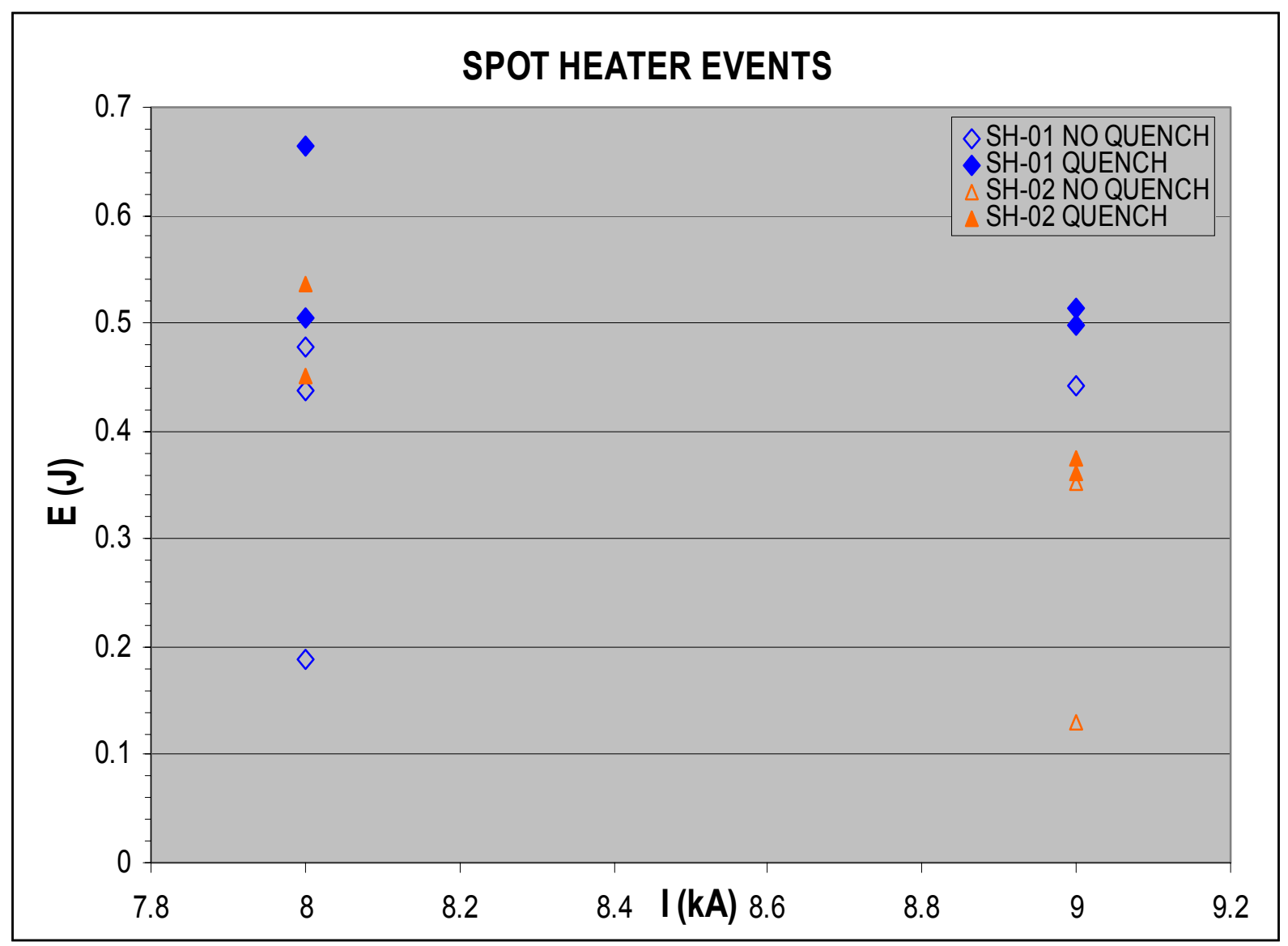

Figure 5.1 Minimum energy studies as a function of current inside the magnet with spot heater induced quenches. 
SM01 a and b Test Results

I|Seminole|Supercon|Subscale Magnet Program|SM First Series|SM01|Test Summar.doc

From the plot we can see:

- The minimum energy required to quench the magnet at $\mathbf{8 k A}$ with a spot heater induced quench in SC01 is between $0.479 \mathrm{~J}$ and $0.504 \mathrm{~J}$.

- The minimum energy required to quench the magnet at $8 \mathbf{k A}$ with a spot heater induced quench in SC02 is less than $\mathbf{0 . 4 5 2 J}$.

- The minimum energy required to quench the magnet at $9 \mathbf{k A}$ with a spot heater induced quench in SC01 is between $0.442 \mathrm{~J}$ and $\mathbf{0 . 4 9 7} \mathrm{J}$.

- The minimum energy required to quench the magnet at $9 \mathbf{k A}$ with a spot heater induced quench in $\mathrm{SC} 02$ is less than $0.352 \mathrm{~J}$ and $\mathbf{0 . 3 6 2} \mathrm{J}$.

The two coils seem to respond differently to excitation and this could be due to geometry difference of the spots (or difference in resistance) and also to the different thermal contact between the spots and the coils. 
SM01 a and b Test Results

||Seminole|Supercon $\mid$ Subscale Magnet Program $\mid$ SM First Series|SM01|Test Summar.doc

\section{RRR MEASUREMENTS}

This measure is usually done during cool down by simply taking the ratio between the resistance of a coil at $300 \mathrm{~K}$ and its resistance at the transition point. The resistance is recorded as a function of time by and it is very easy to see the cliff before the coil becomes superconducting.

In SM01a the cool down was too fast so we made this measurement during warm up (the transition can be clearly seen as well) while in SM01b we were able to see it during cool down. Of course since the coils did not change between the two magnets the RRR values recorded are the same (considering the noise of the read out channels).

\begin{tabular}{|l|l|l|l|l|}
\hline MAGNET & COIL & R 300K (m ) & R 20K (m ) & RRR \\
\hline SM-01 & SC-01 & 99 & 2.5 & 39.6 \\
\hline & SC-02 & 99 & 2.7 & 36.7 \\
\hline \hline SM-01b & SC-01 & 99 & 2.52 & 39.3 \\
\hline & SC-02 & 99 & 2.65 & 37.4 \\
\hline
\end{tabular}

Table 6 RRR measurements for coils SC-01 and SC-02 during the tests of SM-01 and SM-01b. 
SM01 a and b Test Results

||Seminole|Supercon $\mid$ Subscale Magnet Program $\mid$ SM First Series $\mid$ SM01|Test Summar.doc

\section{FAST MOTION EVENTS}

During the test of SM01a and SM01b it was possible for the first time to record many events, which cause the magnet to ring without causing a real quench. Two different types of events were seen during these tests:

- Events occurring at low current with periodic signal of $\mathrm{dV} / \mathrm{dt}$ with relatively low frequency $(1-2 \mathrm{kHz}$ range). These events are not yet fully understood and they are probably due to flux change inside the magnet or local change in temperature.

- Events occurring at higher current with signal which ring at a much higher frequency $(10-20 \mathrm{kHz})$. These events are clearly due to movements of the coil inside during excitation (stick slip motion). In particular it was possible to see that SC-02 (as expected) had a higher number of events occurring since it was not pre-stressed and only spot welded. SC-01 had less events but since it needs more energy to move the amplitude of its oscillations were normally larger than the ones recorded for SC-02. Another thing interesting to report is that we recorded more events for quenches in SM-01b than for quenches in SM-01 since the latter was assembled with a pressure of $13 \mathrm{kPsi}$ while the second one was left loose enough so that the two coils could separate during excitation (the pressure applied during the assembly was $1.5 \mathrm{kPsi}$ ).

- Usually the initial recorded $\mathrm{dV} / \mathrm{dt}$, which starts the oscillation, has a value greater than $100 \mathrm{~V} / \mathrm{s}$.

We now report a series of plots of these studies with some preliminary observations.

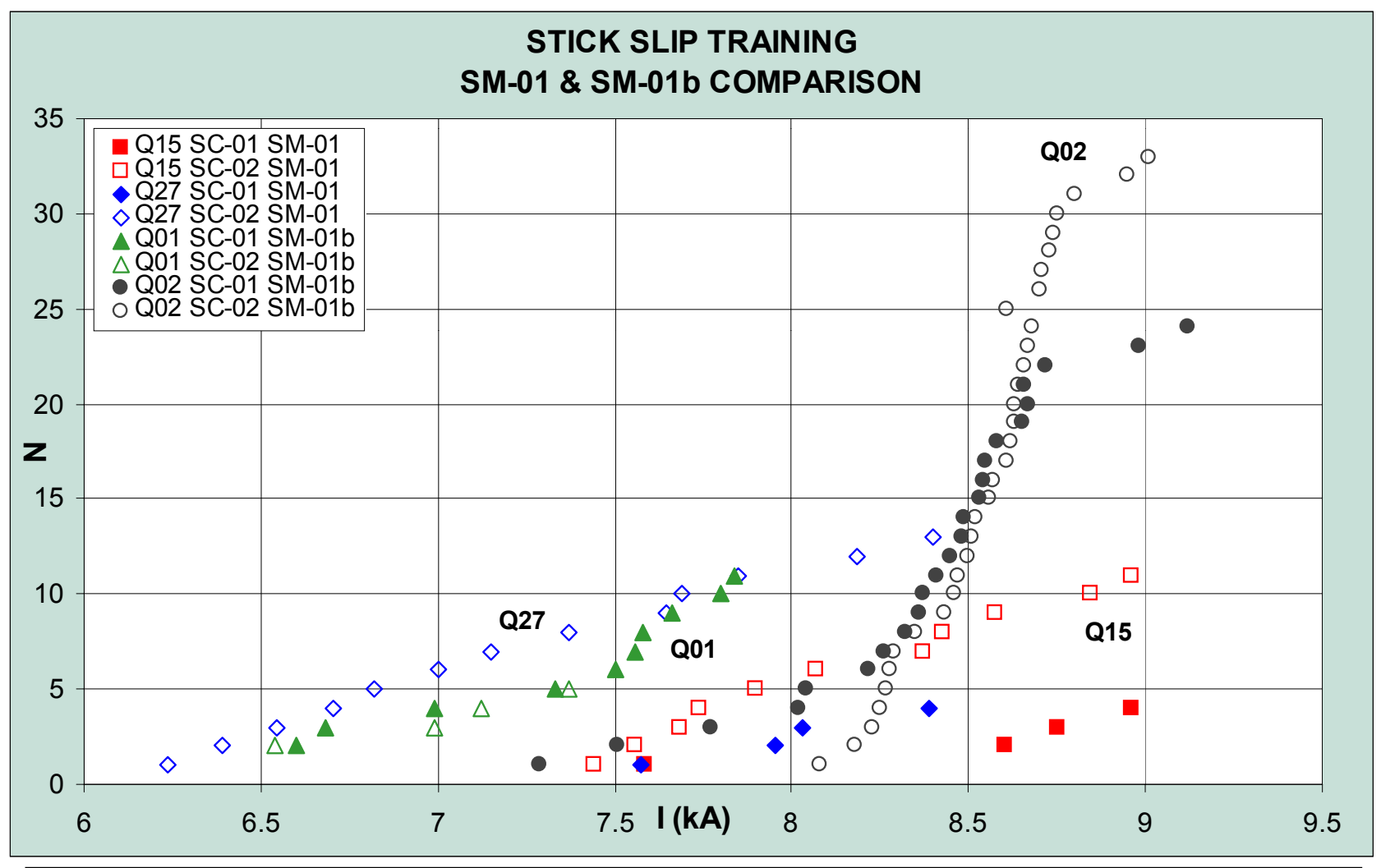

Figure 7.1 Comparison between events in SM-01 and events in SM-01b.

MCoccoli@1bl.gov

LChiesa@,lbl.gov

Page 13 of 16 


\section{SM01 a and b Test Results}

||Seminole|Supercon $\mid$ Subscale Magnet Program $\mid$ SM First Series|SM01|Test Summar.doc

From figure 6 we can see:

- The number of events was higher in SM01b than in SM01a.

- The number of events was higher in SC-02 than in SC-01 (for both the magnets).

- The magnet seems not to remember previous training. For example the motions recorded in quench 27 for SM01a were at lower current than in quench 15.

Analyzing other quenches in SM01b we could confirm the fact that the coils do not remember their previous training and the fast motion events occur at lower current. In general coil SC-02 seems to slip back in current more than SC-01.

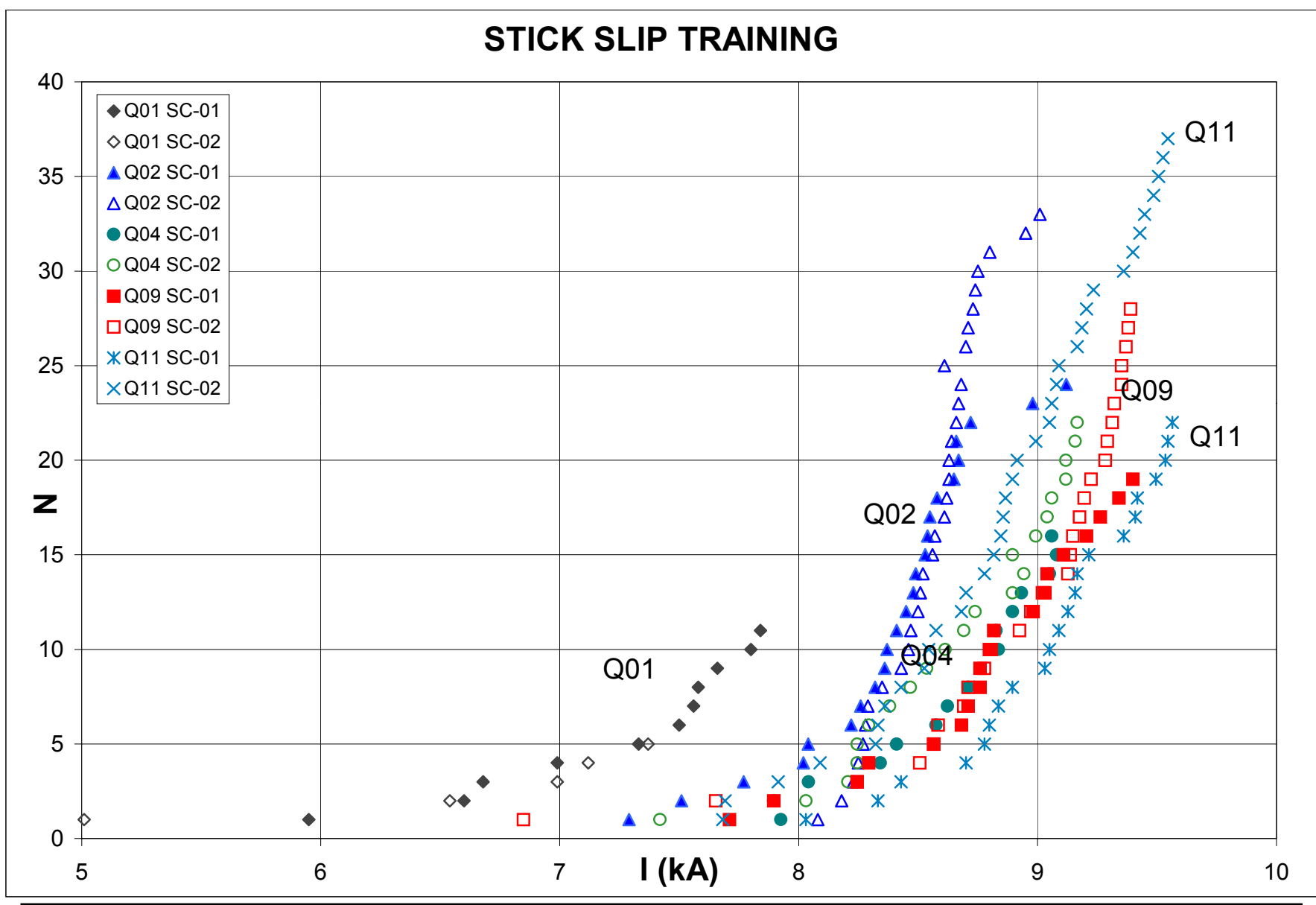

Figure 7.2 Different quenches in SM-01b.

In figure 6 we reported different quenches occurred in SM-01b. As we can see while SC01 seems to remember the previous events (the fast events are recorded at higher current), SC-02 has trained backward in quench 11.

We can also see that the number of events is much higher at higher current (at lower current we recorded slow periodic motion not well understood) since we enter in virgin 


\section{SM01 a and b Test Results}

I|Seminole|Supercon $\mid$ Subscale Magnet Program ISM First Series|SM01|Test Summar.doc

territory for the magnet where we are closer to the critical surface and the magnet is more sensitive to small changes.

We tried also to compare quenches at different ramp rate to see if the magnet creeps instead of slipping at lower ramp rate. If this is the case we should record less events for lower ramp rate or at least smaller amplitudes in the signals. As a result the number of events recorded doesn't seem to be affected by the different ramp rate so probably the magnet is more likely slipping instead of creeping but we will continue in analyzing data in order to better understand the phenomenon.
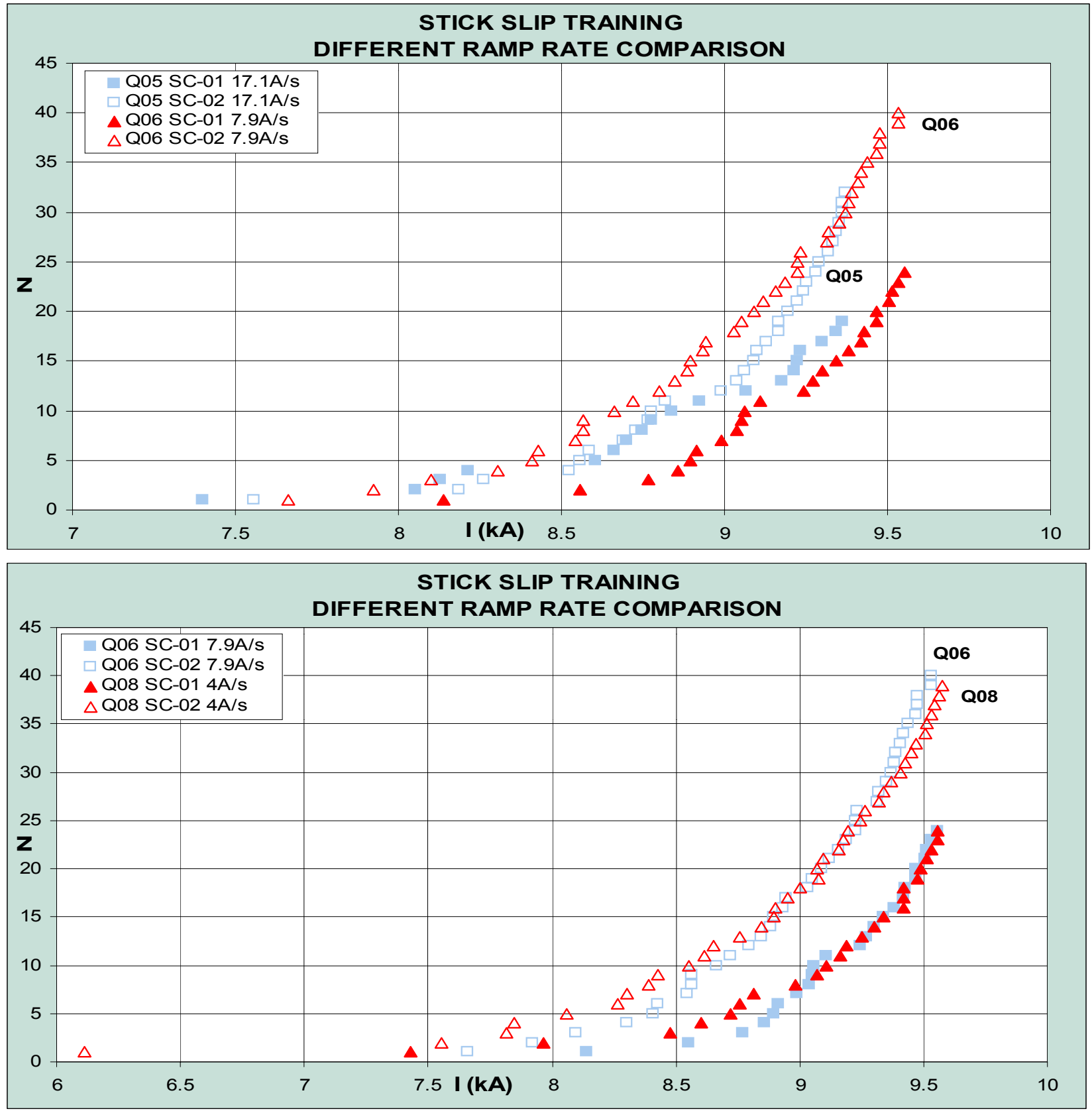

Figure 7.3 Fast motion events as a function of current for quenches at different ramp rate

MCoccoli@1bl.gov

LChiesa@,lbl.gov 
SM01 a and b Test Results

||Seminole|Supercon $\mid$ Subscale Magnet Program $\mid$ SM First Series $\mid$ SM01|Test Summar.doc
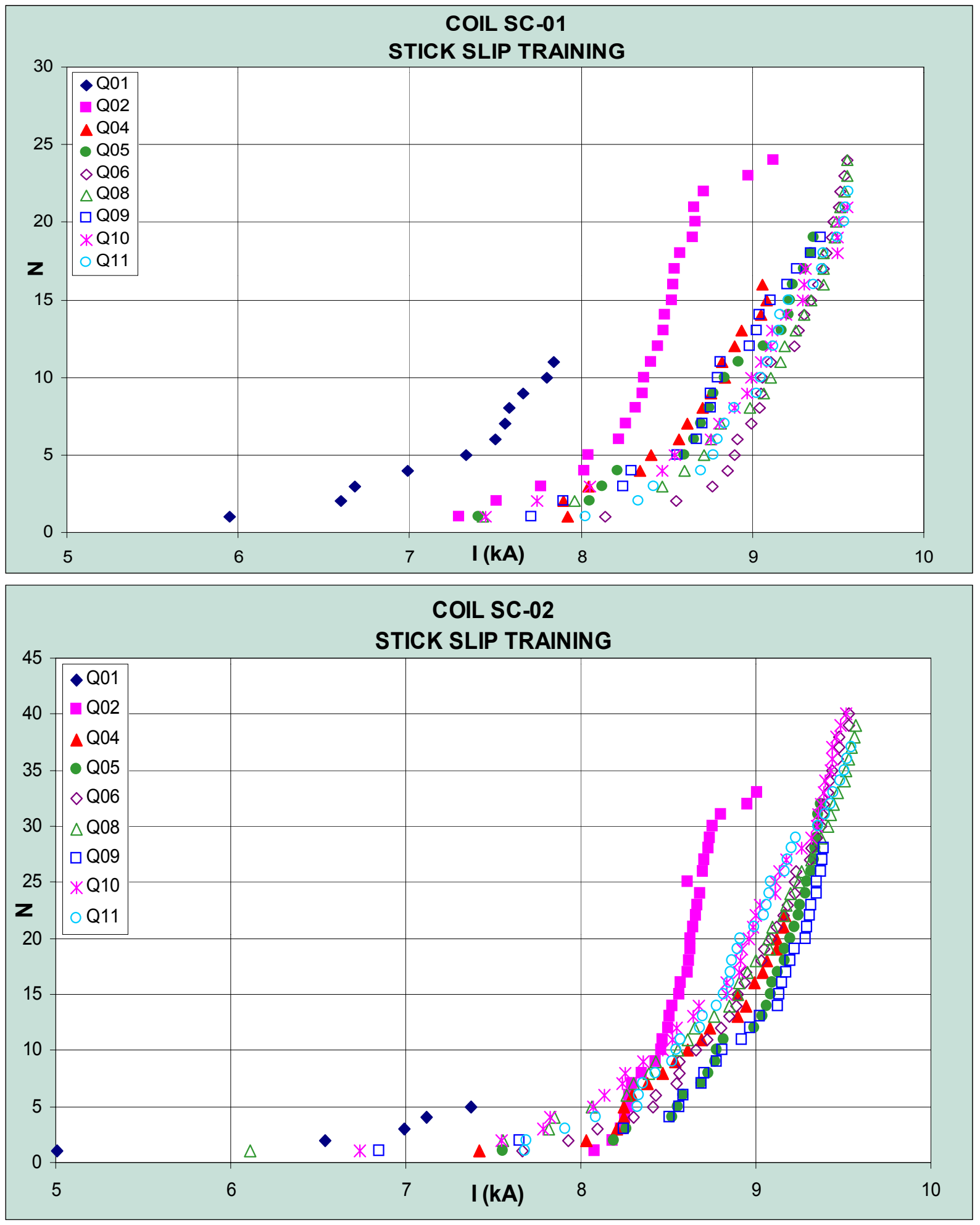

MCoccoli@1bl.gov

LChiesa@,lbl.gov 